\title{
Contenido proteico en los diferentes estadios embrionarios de Talorchestia margaritae (Amphipoda: Talitridae) durante su desarrollo intra-marsupial
}

\author{
Elizabeth Huck, Alberto Martín \& Patricia Miloslavich \\ Universidad Simón Bolívar. Departamento de Estudios Ambientales. Apdo. 89000. Caracas 1086-A, Venezuela. \\ Tel/Fax: 0058-212-9063052; ehuck@intecmar.usb.ve; amartinz@usb.ve; pmilos@usb.ve
}

Recibido 14-X-2005. C Corregido 08-IX-2006. Aceptado 16-III-2007.

\begin{abstract}
Proteic content in the embryonic stages of Talorchestia margaritae (Amphipoda: Talitridae) during its intramarsupial development. The amphipod Talorchestia margaritae Stephesen, 1948, is a semiterrestrial species that inhabits decaying organic material along estuarine shores of the Tuy river, Miranda state, Venezuela. We studied the embryonic development of $T$. margaritae and used biochemical quantitative methods to determine the protein content of embryos in stages of intra-marsupial development, as well as the consumption pattern of these proteins by the embryos. The smallest reproductive females measured $4.6 \mathrm{~mm}$ in body length. A low correlation $\left(\mathrm{R}^{2}=0.2157 ; \mathrm{p}<0.01\right)$ was found between female size and number of eggs in the marsupium. The number of eggs and embryos in the marsupium varied between 3 and 12 egg or embryos/ female for all female sizes, regardless of stage. Five developmental stages were observed: the uncleaved egg, three embryonic stages and the juvenile stage. Mean embryo size increased significantly during embryo development: from $536.4 \pm 28.4 \mu \mathrm{m}$ at stage I up to $798.1 \pm 18.44 \mu \mathrm{m}$ at the juvenile stage (stage V). The protein content decreased from an initial mean value of $4.14 \pm 0.78 \mu \mathrm{g}$ proteins/egg to a final value of $2.02 \pm 0.46 \mu \mathrm{g}$ protein/juvenile. Most of this decrease occurred between stages I and IV, a pattern which could reflect an initial higher consumption of the proteins as a source of energy and tissue formation. At the final stages (between IV and V), there were no significant differences between the protein content of the embryos. Rev. Biol. Trop. 55 (Suppl. 1): 1-8. Epub 2007 June, 29.
\end{abstract}

Key words: Talorchestia margaritae, development, protein content, Peracarida, Venezuela.

El tamaño del huevo es uno de los parámetros que ha recibido mayor atención en el estudio de la reproducción de los invertebrados marinos porque se considera un estimador de la unidad de energía transmitida a la siguiente generación (McEdward y Carson 1987, McEdward y Chia 1991). En especies donde no ocurre una inversión parental postcigótica, la talla del huevo es un buen indicador del modo de desarrollo (Jaeckle 1995). Un ejemplo de esto lo constituyen los gasterópodos del genero Conus, en los cuales la talla del huevo no clivado puede predecir la energía disponible, el largo del período embrionario, la talla y el modo de eclosión (Kohn y Perron 1994). En estas especies la relación talla del huevo/fecundidad es el resultado directo de la inversión materna en la reproducción (Eckelbarger 1986).

La relación entre la estrategia reproductiva y el tamaño del huevo como fuente de energía para el desarrollo de la larva, no es directa en especies que presentan estrategias donde hay inversión en cuidado parental y/o alguna forma de aprovisionamiento extraembrionario. En caso de que exista poecilogonia, se pueden producir tanto larvas con un alto potencial de dispersión (planctotróficas) como larvas que reclutan en zonas inmediatas a la población de origen (lecitotróficas) dependiendo de las condiciones ambientales. Ambos tipos de larvas se desarrollan a partir de huevos de una misma 
talla pero dependiendo de las reservas de que disponga el embrión (Bhaud et al. 1995, Gibson y Chia 1995).

La forma en que son almacenadas las sustancias de reserva dentro de los huevos varía con el grupo. En gasterópodos las proteínas son la fuente principal de aprovisionamiento de energía, ya sea en vitelo contenido dentro de los huevos, o en alguna de las formas de almacenamiento extraembrionario, siendo por tanto el contenido de proteínas, uno de los mejores índices de estimación de la energía disponible para el desarrollo en este grupo (Miloslavich 1995, Ramírez 2002).

En equinodermos (equinoideos y asteroideos) con huevos flotantes que se liberan al agua, se ha encontrado que las reservas son en su mayoría lípidos, que además de almacenar energía, aportan flotabilidad. La composición bioquímica de los huevos de los equinodermos, está aparentemente relacionada al modo nutricional de la larva. En especies que desarrollan una larva lecitotrófica, la composición de sus huevos está dominada por lípidos, mientras que en aquellas productoras de larvas planctotróficas la composición química de sus huevos es básicamente proteica (Turner y Lawrence 1979, Jaeckle 1995, George et al. 1997, Villinski et al. 2002).

En crustáceos se ha encontrado que la composición de las reservas varía, como es el caso del copépodo Paraeuchaeta antarcticala, que almacena principalmente lípidos y proteínas, aumentando el porcentaje de lípidos en los períodos del año donde la disponibilidad de alimento es menor para las larvas (Alonzo et al. 2000). Este modo de almacenamiento compartido entre proteínas y lípidos, es común en crustáceos, observándose en cangrejos (Kattner et al. 2003), camarones (Graeve y Wehrtmann 2003) y anfípodos estuarinos (Volz et al. 2002), siendo los lípidos los que contribuyen mayormente a la energía disponible para el desarrollo. La vitelina (una lipoglicoproteína), es la principal forma de almacenamiento, proveyendo a los embriones tanto de proteínas como de lípidos (Volz et al. 2002). Sin embargo, a pesar de todos estos estudios, el proceso de consumo de estas reservas durante el desarrollo es poco conocido, especialmente para los crustáceos peracáridos.

Los anfípodos son crustáceos peracáridos de tallas que van en su mayoría, de los 2 a los $50 \mathrm{~mm}$ y se les encuentra comúnmente en ecosistemas acuáticos marinos y dulceacuícolas, estando mundialmente distribuidos y existiendo alrededor de 7000 especies descritas. La familia Talitridae comprende alrededor de 200 especies y es el único grupo de anfípodos que coloniza el ambiente terrestre (Serejo 2004).

Durante la reproducción, la hembra deposita los huevos fecundados en un marsupio ventral donde son incubados durante todo su desarrollo. Los huevos se encuentran libres dentro del marsupio y son liberados en una etapa de desarrollo avanzado con una forma muy semejante a la de los adultos (Thiel 1998).

El tamaño de los huevos durante su desarrollo intra-marsupial, aumenta por la incorporación de agua junto con la transformación del vitelo en las estructuras del embrión (Sheader 1996). El desarrollo es sincronizado y se pueden describir al menos cinco estadios diferentes (Quintero et al. 1992, Grassé 1999, Johnson et al. 2001).

El anfípodo Talorchestia margaritae Stephensen, 1948 es semi-terrestre y habita bajo material orgánico en descomposición (Blanco 1980, Venables 1981, Sánchez 1985). Posee un desarrollo intramarsupial típico del grupo, no presentando reservas extravitelinas (gelatinas, huevos nutritivos o canibalismo entre embriones), ni alimentación extraembrionaria por asimilación de materia orgánica disuelta. Estas características lo hacen ideal para el estudio del consumo de las fuentes de energía durante el desarrollo embrionario, ya que se asume que el desarrollo se completa con el suplemento de energía del huevo (Johnson et al. 2001).

El presente trabajo tiene como objetivo estudiar el desarrollo embrionario de T. margaritae y determinar a través de métodos bioquímicos cuantitativos, el contenido de proteínas en los embriones durante los distintos estadios del desarrollo intra-marsupial, así como el patrón de consumo de estas proteínas. 


\section{MATERIALES Y MÉTODOS}

Se recolectaron 146 ejemplares de hembras ovadas de la especie T. margaritae en la desembocadura del río Tuy, Paparo, estado Miranda, Venezuela (10²3’30” N, 6559'12” O) en noviembre de 2004. Los individuos se encontraban en la zona supralitoral húmeda en la costa estuarina del río. Los organismos se recolectaron sobre una bandeja plana de 30 x 20 cm con alcohol etílico al $95 \%$. La arena y el material orgánico traído por el río como hojas, maderas, etc., alrededor de la bandeja, fueron removidos y los individuos que saltaban de este material fueron recolectados en la bandeja. Se depositaron ejemplares de la especie en la Colección de Crustáceos Peracáridos del Museo de Ciencias Naturales de la Universidad Simón Bolívar, número de catálogo MI- 0063.

Las observaciones de los organismos se realizaron con un microscopio estereoscópico ZEISS modelo STEMI-2000 C. Los ejemplares fueron separados utilizando solo las hembras con embriones en sus marsupios, los cuales fueron abiertos para su extracción. Se determinó el estadio de desarrollo de los mismos según la descripción de Grassé (1999), anotando para cada hembra su talla (largo del cuerpo en mm tomado desde la cabeza hasta el telson), el número de huevos o embriones que contenía cada hembra dentro del marsupio, y la talla de los mismos $(\mu \mathrm{m})$.

Las mediciones del contenido de proteínas en huevos y embriones se realizaron a partir de homogeneizados de cinco embriones (provenientes de una misma hembra) en una solución $\mathrm{NaOH} 0.5 \mathrm{~N}$ en tubos Eppendorf. Se utilizó el micro-ensayo (Bio-Rad) basado en el método de Bradford (Bradford, 1976) utilizando BSA (albúmina de suero bovino) como estándar.

Para determinar la existencia de diferencias entre el número de embriones en el marsupio/hembra y el estadio de desarrollo, entre la talla del embrión y el estadio de desarrollo y entre el contenido de proteína/embrión y el estadio de desarrollo, se realizaron ANOVAs y pruebas de comparaciones múltiples de
Tukey. Para determinar el efecto de la talla de la hembra sobre el contenido de proteínas en los embriones y si existe relación entre el tamaño de la hembra y el número de huevos o embriones que incube en su marsupio, se realizaron correlaciones de Pearson entre dichos parámetros.

\section{RESULTADOS}

Desarrollo embrionario y parámetros reproductivos. La talla mínima de las hembras ovadas fue de $4.6 \mathrm{~mm}$, siendo la talla promedio de $7.07 \pm 1.19 \mathrm{~mm}$ (4.6-9.5 mm). Se encontraron cinco estadios de desarrollo embrionario siguiendo las descripciones de Grassé (1999) (Fig. 1, Cuadro 1). El número de huevos y/o embriones por hembra varió entre 3 y 12 para todas las tallas, independientemente del estadío de los mismos. No se encontraron diferencias significativas en el número de embriones por hembra entre los estadios $(\mathrm{p}<0.05)$. Por otra parte, se encontró una correlación significativa baja entre la talla de la hembra y el número de embriones en el marsupio (Pearson, $\mathrm{p}<0.01, \mathrm{R}^{2}=0.2157$, $n=146$ hembras).

A medida que avanza el desarrollo, hay un incremento significativo de la talla de los embriones, desde un promedio para el estadío I (huevo no dividido) de $536.4( \pm 28.4)$ $\mu \mathrm{m}$, hasta un promedio de $798.1( \pm 18.44)$ $\mu \mathrm{m}$ en el estadío V (juvenil) (Fig. 2). No se encontraron diferencias significativas entre las tallas de los embriones en los estadios IV y V (Cuadro 1).

Contenido de proteínas. Se encontraron diferencias significativas en el contenido de proteínas entre el primer estadío y los demás estadios $(p<0.01)$ (Cuadro 1, Fig. 3). Una prueba a posteriori (comparaciones múltiples de Tukey), indicó que entre el estadío 2 y 3 no se encontraron diferencias, pero dichos estadios fueron diferentes al 1, al $4 \mathrm{y}$ al 5 . Entre el 4 y el 5 no se encontraron diferencias, pero resultaron diferentes a todos los demás $(\mathrm{p}<0.05)$. 

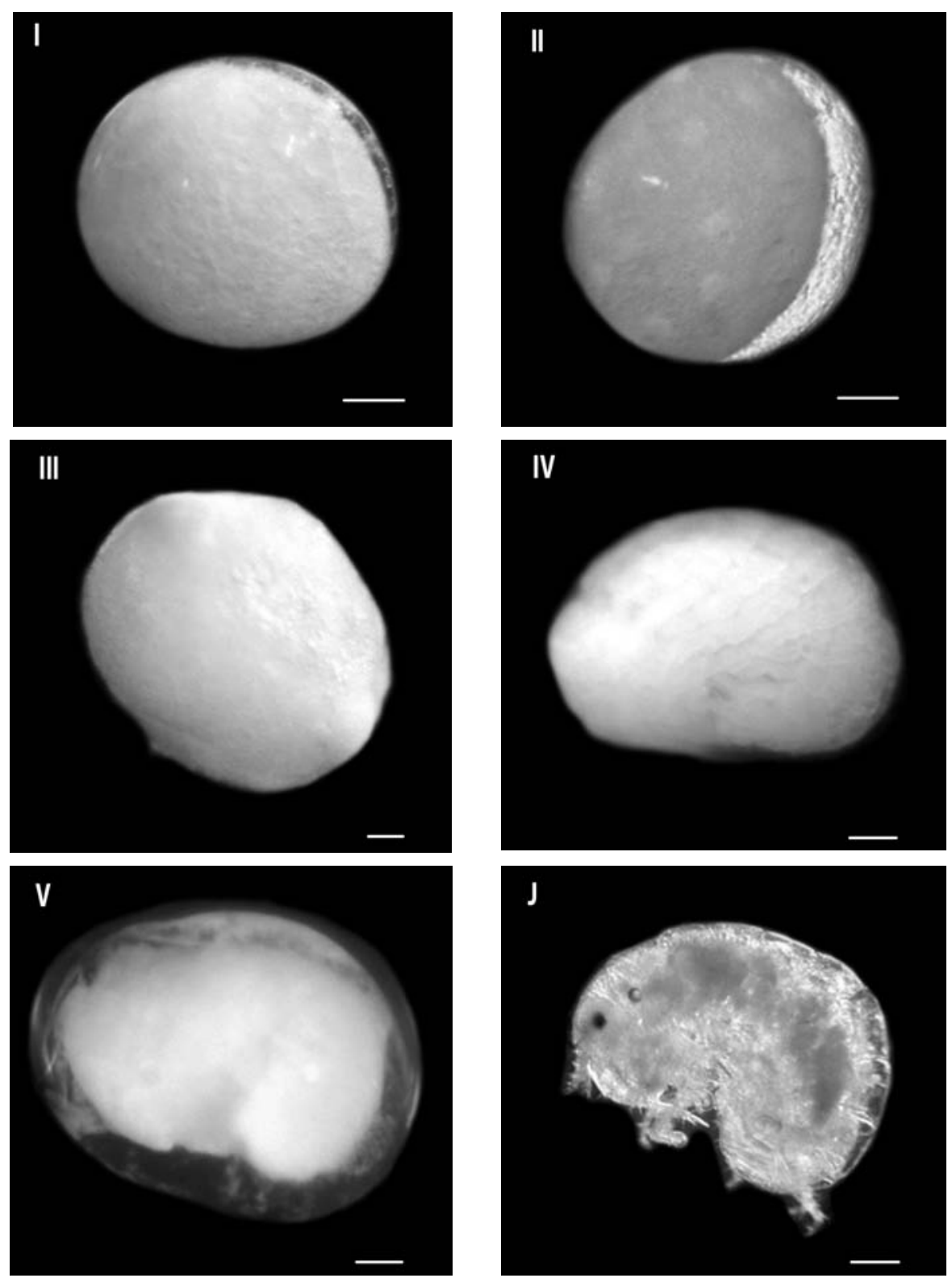

Fig. 1. Estadíos de desarrollo de T. margaritae (basados en la descripción de Grassé 1999). I al V = estadíos de desarrollo intra-marsupio, J= juvenil al momento de la liberación. Escala : $100 \mu \mathrm{m}$.

Fig. 1. Stages of development in T. margaritae (based in the description by Grassé 1999). I to V = intramarsupial stages of development, $\mathrm{J}=$ juvenile at hatching. Scale bar: $100 \mathrm{um}$.

El contenido de proteínas en los embriones disminuyó a medida que avanza el desarrollo, con un contenido promedio inicial de 4.14 $( \pm 0.78) \mu \mathrm{g} / \mathrm{huevo}$, hasta un promedio de 2.02 $( \pm 0.46) \mu \mathrm{g} / \mathrm{juvenil}$ en el estadío V (Fig. 3).

\section{DISCUSIÓN}

Desarrollo embrionario y parámetros reproductivos. Al no encontrar diferencias significativas en el número de embriones por 


\section{CUADRO 1}

Estadios del desarrollo embrionario intramarsupial de T. margaritae y el contenido de proteínas de cada uno.

TABLE 1

Stages of intramarsupial embryonic development of T. margaritae and their protein content.

\begin{tabular}{|c|c|c|c|c|}
\hline Estadío & Descripción & $\begin{array}{c}\text { Número de embriones } \\
\text { por hembra }\end{array}$ & $\begin{array}{l}\text { Talla de los embriones } \\
\qquad(\mu \mathrm{m})\end{array}$ & $\begin{array}{l}\text { Contenido de prote } \\
\text { por embrión }(\mu \mathrm{g}\end{array}$ \\
\hline I & $\begin{array}{l}\text { Embrión no divi- } \\
\text { dido, vitelo llena por } \\
\text { completo el espacio del } \\
\text { huevo }\end{array}$ & $\begin{array}{c}7.43 \pm 2.13 \\
\mathrm{n}_{1}=28 \\
(3-11)\end{array}$ & $\begin{array}{c}536.39 \pm 28.47 \\
\mathrm{n}_{2}=30 \\
(510-600)\end{array}$ & $\begin{array}{c}4.14 \pm 0.78 \\
\mathrm{n}_{3}=30 \\
(2.0-5.8)\end{array}$ \\
\hline II & $\begin{array}{l}\text { Presencia del surco } \\
\text { medio (blastoporo), } \\
\text { pequeña separación } \\
\text { entre embrión y mem- } \\
\text { brana del huevo }\end{array}$ & $\begin{array}{c}7.71 \pm 2.01 \\
\mathrm{n}_{1}=35 \\
(4-11)\end{array}$ & $\begin{array}{c}632.93 \pm 43.5 \\
\mathrm{n}_{2}=35 \\
(586.5-780)\end{array}$ & $\begin{array}{c}3.46 \pm 1.31 \\
n_{3}=35 \\
(1.30-6.20)\end{array}$ \\
\hline III & $\begin{array}{l}\text { Separación del embrión } \\
\text { de la membrana del } \\
\text { huevo, se comienza a } \\
\text { observar la formación } \\
\text { de apéndices }\end{array}$ & $\begin{array}{c}8.22 \pm 1.86 \\
\mathrm{n}_{1}=18 \\
(5-12)\end{array}$ & $\begin{array}{c}720.20 \pm 30.85 \\
\mathrm{n}_{2}=30 \\
(688.5-780)\end{array}$ & $\begin{array}{c}3.04 \pm 1.44 \\
\mathrm{n}_{3}=30 \\
(1.3-6.2)\end{array}$ \\
\hline IV & $\begin{array}{l}\text { Se reduce el vitelo y se } \\
\text { observa el desarrollo } \\
\text { de ojos }\end{array}$ & $\begin{array}{c}0.39 \pm 1.69 \\
\mathrm{n}_{1}=33 \\
(5-11)\end{array}$ & $\begin{array}{c}787.73 \pm 20.11 \\
\mathrm{n}_{2}=33 \\
(730-816)\end{array}$ & $\begin{array}{c}2.17 \pm 0.65 \\
\mathrm{n}_{3}=33 \\
(1.2-3.2)\end{array}$ \\
\hline V & $\begin{array}{l}\text { El anfípodo esta com- } \\
\text { pletamente formado }\end{array}$ & $\begin{array}{c}8.38 \pm 1.62 \\
\mathrm{n}_{1}=32 \\
(5-11)\end{array}$ & $\begin{array}{c}798.09 \pm 18.44 \\
\mathrm{n}_{2}=30 \\
(758-841.5)\end{array}$ & $\begin{array}{c}2.02 \pm 0.46 \\
\mathrm{n}_{3}=30 \\
(1.2-2.8)\end{array}$ \\
\hline
\end{tabular}

Los valores representan los promedios \pm la desviación estándar; $\mathrm{n}_{1}=$ número de hembras, $\mathrm{n}_{2}$ = número de embriones medidos, $\mathrm{n}_{3}=$ número de réplicas en la determinación de proteínas. Los números en paréntesis representan los valores mínimos y máximos.

Values represent mean \pm standard deviation, $n_{1}=$ number of females, $n_{2}=$ number of measured embryos, $n_{3}=$ replicate number in protein determination. Numbers in parenthesis represent minimal and maximal values.

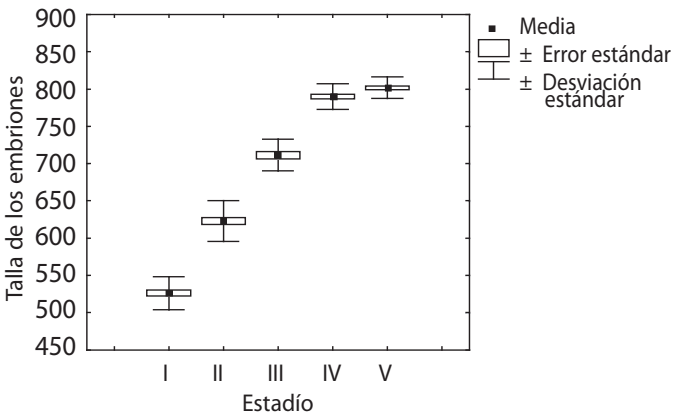

Fig. 2. Talla de los embriones en los estadíos de desarrollo intramarsupial de T. margaritae (media, error estándar y desviación estándar).

Fig. 2. Size of embryos at the stages of intramarsupial development of T. margaritae (mean, standard error and standard deviation).

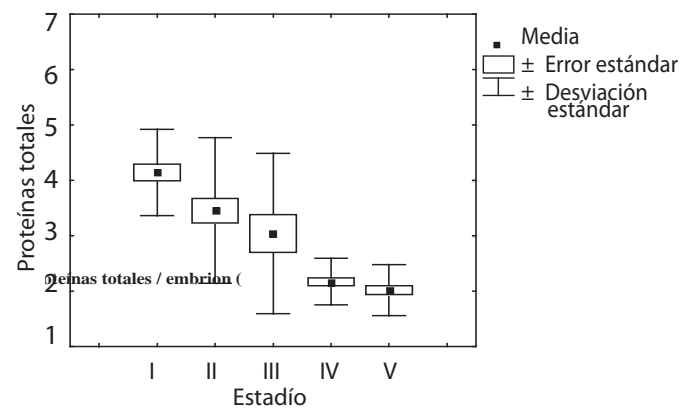

Fig. 3. Proteínas totales presentes en los embriones en los estadíos de desarrollo de T. margaritae (media, error estándar y desviación estándar).

Fig. 3. Total protein per embryo at the developmental stages of T. margaritae (mean, standard error and standard deviation). 
hembra entre los estadios, se presume que no hay un cambio en el número de embriones dentro del marsupio durante el desarrollo, es decir, todos los embriones que se depositan en el marsupio se están desarrollando lo cual corrobora los datos de Blanco (1980) y Sánchez (1985) para T. margaritae en la zona oriental de Venezuela y los datos de Lalitha et al. (1990) para T. martensis. La existencia de una correlación positiva entre la talla de la hembra y el número de embriones en el marsupio de T. margaritae ha sido reportada previamente por Blanco (1980) y Sánchez (1985), indicando que la talla de la madre influye en la energía disponible para ser invertida en la reproducción, estando una hembra de mayor tamaño en capacidad de invertir mayor cantidad de energía, aunque no tenga influencia en la talla de los huevos (como un mayor aprovisionamiento para cada uno de los embriones), si resulta en un mayor número de embriones por camada.

La talla mínima de las hembras ovadas $(4.6 \mathrm{~mm})$ es inferior a la talla reportada para la misma especie por Sánchez (1985) de $6.3 \mathrm{~mm}$, y por Venables (1981) de $5.5 \mathrm{~mm}$, pudiendo ser esto un reflejo del abundante alimento disponible para las hembras en esta localidad. En relación con esto, el Río Tuy capta la mayor parte de los efluentes del polo de crecimiento económico, urbano e industrial más importante de Venezuela, deponiéndose las aguas servidas de una población de aproximadamente 6 millones de habitantes y que descarga directamente sobre la zona de muestreo; mientras que en playa El Dique en Cumaná (Venables 1981), o en la Isla de Margarita (Sánchez 1985), no existen descargas de materia orgánica de estas magnitudes.

Como se evidencia en las figuras 2 y 3 , se observa un mayor aumento de la talla en los primeros tres estadios, lo cual coincide con el período de mayor consumo de proteínas.

Contenido de proteínas. La disminución del contenido de proteínas es mayor entre los estadios I al III, presentándose también la mayor varianza a este respecto. Este patrón refleja una mayor utilización de las proteínas como fuente de energía y formación de tejidos en los estadios iniciales, mientras que en estadios finales la diferencia disminuye, al mismo tiempo que lo hace la varianza.

Hacia el final del desarrollo, hay una menor variación en el contenido de proteínas en los embriones, ya que los embriones han utilizado la mayoría de la proteína disponible y el metabolismo y crecimiento se lleva a cabo a partir de fuentes alternativas como lípidos. Este patrón en el uso de las proteínas se ha observado en el desarrollo embrionario de otros crustáceos peracáridos como Mysidium columbiae (Zimmer) (Carbonini y Miloslavich 2005). La concentración inicial de proteínas en los huevos de T. margaritae es relativamente baja si se compara con el contenido de proteínas de gasterópodos con huevos de tamaños similares (Miloslavich 1995), pudiendo ser esto indicativo de que para T. margaritae la fuente de energía principal serían los lípidos, como ha sido informado para otros crustáceos (Graeve y Wehrtmann 2003).

Si tomamos en cuenta que parámetros reproductivos como fecundidad, talla del huevo, contenido energético y número de los mismos están directamente ligados a la adecuación de los individuos de una especie, estos podrían fluctuar frente a condiciones ambientales alteradas (Levitan 2000). En el caso de T. margaritae, existe una variación en el número de huevos por hembra y la talla de la primera reproducción, la cual podría depender de la disponibilidad de alimentos (Levitan 2000). Las poblaciones estudiadas incluyen las localidades del Río Tuy (presente estudio), la Isla de Margarita (Sánchez 1985) y la costa oriental de Venezuela (Blanco 1980, Venables 1981), en donde el contenido de materia orgánica particulada en las playas como fuente de alimento, es definitivamente diferente, siendo sumamente alta su disponibilidad en el Río Tuy (Martín 1987). Estas diferencias reproductivas observadas, también podrían extenderse al contenido energético de los 
huevos y embriones, sugiriendo que la inversión en reproducción podría ser un carácter con plasticidad fenotípica.

Este trabajo es una aproximación inicial al estudio de la energética del desarrollo de T. margaritae, siendo el paso siguiente la evaluación de otros componentes de las reservas energéticas de los embriones como lípidos y carbohidratos.

\section{RESUMEN}

El anfípodo Talorchestia margaritae Stephesen, 1948, es una especie semi-terrestre, que habita bajo material orgánico en descomposición, en la desembocadura del río Tuy, estado Miranda, Venezuela. Estudiamos el desarrollo embrionario de T. margaritae y determinamos con métodos bioquímicos cuantitativos el contenido de proteínas en los embriones, durante los estadios del desarrollo intramarsupial, así como su patrón de consumo de proteínas. La talla mínima de hembras ovadas fue de $4.6 \mathrm{~mm}$ de longitud corporal. Se encontró una correlación baja $\left(\mathrm{R}^{2}=\right.$ 0.2157; $\mathrm{p}<0.01$ ) entre la talla de la hembra y el número de huevos en el marsupio. El número de huevos y embriones en el marsupio varió entre 3 y 12 huevos o embriones/ hembra, para todas las tallas de hembra independientemente del estadío. Se observaron cinco estadios de desarrollo: el huevo no dividido, tres estadios de embriones intramarsupiales y el juvenil. A medida que avanza el desarrollo, hay un incremento significativo de la talla de los embriones, desde un promedio para el estadío I (huevo no dividido) de $536.4( \pm 28.4) \mu \mathrm{m}$, hasta un promedio de $798.1( \pm 18.44) \mu \mathrm{m}$ en el estadío V (juvenil). El contenido de proteínas disminuyó desde un promedio inicial de 4.14 $( \pm 0.78) \mu \mathrm{g}$ proteínas/huevo, hasta un promedio final de $2.02( \pm 0.46) \mu g$ proteína/juvenil. La disminución es mayor entre los estadios I y IV, pudiendo este patrón reflejar una mayor utilización inicial de las proteínas como fuente de energía y formación de tejidos, mientras que en estadios finales, no hay diferencias significativas entre el contenido de proteínas de los estadios IV y V.

Palabras clave: Talorchestia margaritae, desarrollo, contenido proteico, Peracarida, Venezuela.

\section{AGRADECIMIENTOS}

Agradecemos a Yusbelly J. Díaz el apoyo logístico en la recolección, identificación y catalogación del material biológico en el Museo de Ciencias Naturales de la Universidad Simón Bolívar. Este proyecto fue financiado por el Decanato de Investigación y Desarrollo, Universidad Simón Bolívar.

\section{REFERENCIAS}

Alonzo, F., P. Mayzaud \& S. Razouls. 2000. Egg production, population structure and biochemical composition of the subantarctic copepod Paraeuchaeta antarctica in the Kerguelen Archipelago. Mar. Ecol. Prog. Ser. 205: 207-217.

Bhaud, M., J. Cha, J. Duchene, C. Nozais \& D. Martín. 1995. Larval biology and benthic recruitment: new prospect on the role of egg-masses and modelling life cycle regulation. Sci. Mar. 59: 103-117.

Blanco, J. 1980. Contribución al conocimiento de la biología de T. margaritae Stephensen 1948 (Amphipoda: Talitridae). Tesis de Licenciatura. Universidad de Oriente, Cumaná, Venezuela. 44 p.

Bradford, M. 1976. A rapid and sensitive method for the quantification of microgram quantities of protein utilizing the principle of protein dye binding. Anal. Biochem. 72: 248-254.

Carbonini, A.K. \& P. Miloslavich. 2005. Desarrrollo intramarsupial y determinación de proteínas en la especie Mysidium columbiae (Zimmer) (Mysidea: Peracarida). XI Congreso de Ciencias del Mar (COLACMAR), Viña del Mar, Chile. p. 407 (Resumen).

Eckelbarger, K. 1986. Vitellogenic mechanism and the allocation of energy in offspring in polychaetes. Bull. Mar. Sci. 39: 426-443.

George, S.B., C.M. Young \& L.B. Fenaux. 1997. Proximate composition of eggs and larvae of the sand dollar Encope michelini (Agassiz): the advantage of higher investment in planktotrophic eggs. Invert. Reprod. Dev. 32: 11-19.

Gibson, G. \& F. Chia. 1995. Developmental variability in the poecilogonous opistobranch Haminaea callidegenita: life-history traits and effects of environmental parameters. Mar. Ecol. Prog. Ser. 121: 139-155.

Graeve, M. \& I.S. Wehrtmann. 2003. Lipid and fatty acid composition of Antarctic shrimp eggs (Decapoda: Caridea). Polar Biol. 26: 55-61

Grassé, P. 1999. Traité de zoologie : anatomie, systématique, biologie. Tome VII. Fascicule IIIA. Crustacés Péracarides. Memoires de’l Institut Oceanographique, París, Francia. 450 p. 
Jaeckle, W.B. 1995. Variation in size, energy content and biochemical composition of invertebrate eggs: correlates to the mode of larval development, p. 49-78. In L.R McEdward (ed.). Ecology of Marine Invertebrate Larvae. Powell's, Boca Ratón, Florida, EEUU.

Johnson, W., M. Stevens \& L. Watling. 2001. Reproduction and development of marine peracaridans. Adv. Mar. Biol. 39: 105-260.

Kattner, G., M. Graeve, J. Calcagno, G. Lovrich, S. Thatje \& K. Anger. 2003. Lipid, fatty acid and protein utilization during lecithotrophic larval development of Lithodes santolla (Molina) and Paralomis granulosa (Jacquinot). Exp. Mar. Biol. Ecol. 292: 61-74.

Kohn, A. \& F. Perron. 1994. Life History and Biogeography: Patterns in Conus, Oxford University, Nueva York, EEUU. 122 p.

Levitan, D. 2000. Optimal egg size in marine invertebrates: theory and phylogenetic analysis of the critical relationship between egg size and development time in echinoids. Am. Nat. 156: 175-192.

Lalitha, M., K. Shyamasundari \& K. Hanumantha. 1990. Effects of salinity and temperature on the development of eggs in amphipod Tallorchestia martensis (Weber) (Crustacea: Amphipoda). Ophelia 16: 117-127.

Martín, A. 1987. Estudio integral de la contaminación acuática en la cuenca del río Tuy (Edos. AraguaMiranda). Tesis de Maestría en Administración Ambiental, Instituto Universitario Politécnico de las Fuerzas Armadas Nacionales (IUPFAN), Caracas, Venezuela. 277 p.

McEdward, L. \& S. Carson. 1987. Variation in egg organic content and its relationship with egg size in the starfish Solaster stimpsoni. Mar. Ecol. Prog. Ser. 37: 159-169.

McEdward, L. \& F. Chia. 1991. Size and energy content of eggs from echinoderms with pelagic lecithotrophic development. Exp. Mar. Biol. Ecol. 147: 95-102.

Miloslavich, P. 1995. A morphological, biochemical and electrophoretic study of the embryonic development in temperate and tropical prosobranchs. Ph. D.
Thesis. Université du Québec at Rimouski, Québec, Canada. 129 p.

Quintero, H., C. Vain \& P. Moreno. 1992. Seguimiento del ciclo reproductivo en el anfipodo marino Oarhyale hawaiensis (Dana) (Gammaridea: Hyalidae). Inst. Invest. Mar. 21: 85-93.

Ramírez, E. 2002. Fecundity and life-history strategies in marine invertebrates. Adv. Mar. Biol. 43: 87-170.

Sánchez, L.A. 1985. Algunos aspectos biológicos de T. margaritae Stephensen, 1948 (Amphipoda: Talitridae), de la Isla de Margarita, Venezuela. Tesis de Licenciatura. Universidad de Oriente, Cumaná, Venezuela. $51 \mathrm{p}$.

Serejo, C.S. 2004. Talitridae (Amphipoda, Gammaridea) from the Brazilian coastline. Zootaxa 646: 1-29.

Sheader, M. 1996. Factors influencing egg size in the gammarid amphipod Gammarus insensibilis. Mar. Biol. 124: 519-526.

Thiel, M. 1998. Reproductive biology of a deposit-feeding amphipod, Casco bigelowi, with extended parental care. Mar. Biol. 132: 107-116.

Turner, R.L. \& G.W. Lawrence. 1979. Volume and composition of echinoderm eggs: implications for the use of egg size in life-history models, p. 25-40. In S.E. Stancyk (ed.). Reproductive Ecology of Marine Invertebrates. University of South Carolina, Columbia, Carolina del Sur, EEUU.

Venables, B.J. 1981. Aspects of the population biology of a Venezuelan beach amphipod, Talorchestia margaritae (Talitridae), including estimates of biomass and daily production and respiration rates. Crustaceana 41: 271-285.

Villinski, J.T., J.C. Villinski, M. Byrne \& R.A. Raff. 2002. Convergent maternal provisioning and lifehistory evolution in echinoderms. Evolution 56: 764-775.

Volz, D., T. Kamaguchi \& T. Chandler. 2002. Purification and characterization of the common yolk protein, vitellin, from the estuarine amphipod Leptocheirus plumulosos. Prep. Biochem. Biotechnol. 32: 103-116. 